\title{
Insectes Sociaux Best Paper 2019
}

○ International Union for the Study of Social Insects (IUSSI) 2020

It is a pleasure to announce that the winner of the 2019 Best Paper Award is "Vitellogenin and vitellogenin-like gene expression patterns in relation to caste and task in the ant Formica fusca" by Claire Morandin, Anna Hietala and Heikki Helanterä at the University of Helsinki, Finland.

Dr. Morandin and colleagues investigated the functional roles of four members of the vitellogenin gene family by comparing RNA expression levels among different social phenotypes in the ant, Formica fusca (Morandin et al. 2019). By comparing females that lay more versus fewer eggs (queens vs. workers, nurse workers vs. foraging workers, and workers in queenless vs. queenright colonies), their comprehensive study confirmed the primary role of conventional $\mathrm{Vg}$ as an egg yolk protein gene, as this gene was more strongly expressed in queens. Morandin et al. also suggested roles for the more mysterious, less well understood Vg-like genes, which may have acquired roles unrelated to egg production per se, but crucial to understanding reproductive division of labour. For instance, in F. fusca, $\mathrm{Vg}$-like C expression levels were higher in foragers than in either queens or non-foraging workers (nurses).

Claire Morandin received her PhD from the University of Helsinki and currently holds an EMBO long-term fellowship with Lausanne University (Switzerland), studying molecular evolution and caste determination in social insects.

Anna Hietala successfully completed her master's thesis with this project, receiving her master's degree from the University of Helsinki. She is currently teaching biology and geography in an upper elementary school in Helsinki.

Heikki Helantera is an associate professor at the University of Oulu, where his group studies social evolution, genetics and behaviour in ants, especially focusing on the genus Formica.

The Best Paper Award is selected annually by the editors and editorial board of Insectes Sociaux after extensive review and consultation. The board consists of prominent scientists studying arthropod social biology at leading universities from around the world. Insectes Sociaux publishes original scientific studies and review articles about social arthropods.

\section{Reference}

Morandin C, Hietala A, Helanterä H (2019) Vitellogenin and vitellogenin-like gene expression patterns in relation to caste and task in the ant Formica fusca. Insectes Soc 66:519-531 